[Hogg, L. (2009). Transcending Monocultural Life Experiences for Pakeha Trainee Teachers. New Zealand Annual Review of Education, 18, 89106]

\section{Transcending Monocultural Life Experiences for Pakeha Trainee Teachers}

\section{LINDA HOGG}

\section{Abstract:}

As New Zealand society becomes increasingly diverse, teachers remain a relatively homogenous group. It is important for teacher training to help prospective Pakeha teachers to transcend monocultural life experiences, to support their development as effective multicultural educators. International research evidences the lack of self-awareness which monocultural life experience can create, resulting in unconscious and unintended intolerance towards other perspectives and values.

This article reviews three selected training strategies: teaching experience, case method and interactive performance, in relation to their potential in addressing this issue. It concludes by discussing implications for teacher training institutions and future research.

$\mathrm{t}$ is always heartening for a teacher educator to experience the passion and love which teacher trainees bring to their studies. Typically they aim to be teachers who create learning experiences which are enjoyed, valued and effective for all. However, in helping prospective teachers to achieve that dream, it is necessary for teacher educators to raise trainees' awareness of attitudes and beliefs which they hold, often unconsciously, to enable reflection on how these beliefs may impact on teaching effectiveness for diverse students. Many "white" teacher trainees from monocultural privileged backgrounds tend to be "unaware of their personal intellectual bias and monocultural encapsulation" (King, 2004, p. 80). Unaware of themselves as culturally located beings, they experience themselves as "normal", and unconsciously apply their perspectives and values to all (Delpit, cited by
90 Linda Hogg

Darling-Hammond, 2002b). Such pre-service teachers also lack experience of discrimination and are reluctant to discuss race and racism (Sleeter, 2008). Thus, despite the sincere passion and love brought to their teacher training experience, prospective teachers often unwittingly continue hegemonic practices. Hence the need to support trainee teachers to make explicit those attitudes and beliefs which powerfully influence their professional actions, despite being invisible to the teacher.

Essential knowledge for an effective multicultural educatorincludes declarative knowledge (facts about aspects of diversity, needs of diverse learners, and links between these); procedural knowledge (including professional skills); and conditional knowledge (identifying and making a commitment to taking suitable action related to the specific circumstances) (Aguilar \& Pohan, 1996). Even when teachers have multicultural education knowledge, without supportive attitudes they will choose not to act on it, not realising its significance. Multiple studies provide evidence of the fundamental impact of privately held beliefs and attitudes on teachers' work, including daily professional behaviour and interaction with students (Aguilar \& Pohan, 1996). In New Zealand, research exists which describes widespread deficit theorizing by teachers regarding Māori students (Bishop, Berryman, Tiakiwai, \& Richardson, 2003), and highlights the negative impact of this upon Māori learners. Once again, many of these teachers are simply doing their best with their Māori students, but unfortunately unconscious or sub-conscious attitudes are holding them back.

Bondy and Savage (2004) found that pre-service teachers self-reported attitudes and beliefs regarding different cultural groups which they knew were valued by their lecturers, but which contradicted their actual beliefs, highlighting a challenge for teacher-educators to break through a perception of multicultural educational issues as politically correct, but with limited real value. The challenge is to raise awareness of the nature and relevance of the issue, so deep and real attitudinal shifts may be possible. We know that students can learn to work successfully with teachers from cultures other than their own (Hawk, Cowley, Hill \& Sutherland, 2002). To be effective, teachers need to understand the importance of culture for each student, be able to relate to them, and support their identity and learning as cultural beings (Bishop et al., 2003; Hawk et al., 2002).

Despite recent positive trends in National Certificate of Educational Achievement (NCEA) results, ultimately Māori (and Pasifika) student 
achievement data evidence significant room for improvement in teachers' ability to address the learning needs of diverse students successfully, confirming that teacher education must seek to develop professionals who are capable of transcending current standards of practice, to achieve "deep restructuring" (Hilliard, 1991, cited by Gillette, 1996, p. 128).

This issue has become urgent, as New Zealand teachers work with increasingly ethnically diverse classes, but remain a relatively homogenous group themselves. Students who are Māori, Pasifika and Asian are increasing proportionately in New Zealand schools, with projections indicating that 35 percent of students in 2021 will be Māori or Pasifika (Ministry of Education, 2002)

New Zealand government policy provides strong directives regarding inclusivity for culturally diverse learners as a key priority of the compulsory education sector. Section 61 of the Education Act requires that school charters establish the mission, aims, objectives, directions, and targets of school Boards of Trustees (BOTs), to give effect to the Government's National Education Guidelines (NEGs) and the BOT's priorities. The NEGs specifically require schools to address the special place of Māori, in accordance with Te Tiriti o Waitangi, and call for programmes which allow all students equal opportunity to realise their potential. BOTs also report to the Ministry of Education annually regarding the alignment of their school's strategic plan with the National Administration Guidelines (NAGs). The NAGs require schools to identify students who are not achieving, or who are at risk of not achieving, and develop teaching and learning strategies to meet their needs. Most recently, the New Zealand Curriculum (NZC), required to be implemented by 2010, provides a "framework designed to ensure that all young New Zealanders are equipped with the knowledge, competencies and values they will need to be successful citizens in the twenty first century" (Ministry of Education, 2007, p. 4). Principles of the NZC, which "should underpin all school decision-making" (p. 9)include high expectations and inclusion, affirming the government's commitment to a school system which achieves high achievement as well as social equity.

This raises the question, illustrated by Figure 1 below, of what type of training strategy can successfully support the development of teachers who can meet the needs of diverse students? What experiences can be incorporated into training programmes, which are both manageable for the provider, and effective in their ability to unsettle long-held unconscious beliefs and values? An informal survey of post-graduate students, which asked them to reflect on the nature of events which caused them personally to experience a change of attitude to another ethnic group, suggests that experiential learning holds the most promise.

\section{Experiential learning: \\ through building authentic connections and} relationships

\section{Vicarious learning: \\ through studying}

literature and film
Academic learning:

through reading information and studying relevant statistical data

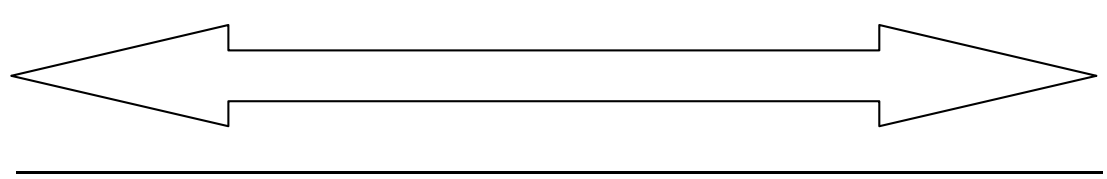

Figure 1 Ways to develop understanding of individuals from different ethnic groups

The following sections of this article discuss the features, strengths and limitations of three training strategies, in relation to this challenge.

\section{Teaching Experience (TE)}

The TE is a widely embedded training strategy in New Zealand teacher education, involving trainees spending a block of time in a school, and taking on scaffolded teaching duties. Each trainee is buddied with associate teachers (ATs: practising teachers in the host school) and is timetabled for involvement with their classes. ATs provide guidance and feedback to trainees to support their professional growth. Currently the graduate programme for primary and secondary teachers at Victoria University of Wellington (VUW) includes two TEs of seven weeks each.

Pre-service teachers training at the VUW College of Education highly value TEs, typically citing them as the most valuable learning experience of the programme, echoing international opinion of their peers (Sleeter, 2008, p. 568).

TEs offer an experiential learning opportunity to pre-service teachers, to "apply what they are learning directly to the classroom in real time. This helps to prevent concerns about race, class and culture 
becoming objectified, oversimplified, or an abstraction that could result mostly in 'otherising' students" (Darling-Hammond, 2002a, p. 4). The actual benefits arising from potential gains are dependent on a number of variables, including the demographic structure of the student community in the assigned school. There is value in strategic management of TE placements, to ensure that each pre-service teacher spends time in at least one school with an ethnically diverse population. For pre-service teachers based in smaller communities, completing their studies online, it may be difficult to achieve this without leaving their community. Placement in an ethnically diverse school, however, does not guarantee that pre-service teachers will be professionally enriched by this experience. That outcome depends on trainees getting to know the students, developing their understanding and appreciation of members of these cultural groups.

Gillette (1996) found that, when placed in a school community where the lives of students were significantly different from their own experience, most pre-service teachers responded either by resisting or rethinking. "Resisters ... resisted becoming critically conscious of their own attitudes, beliefs and stereotypes" (Gillette, 1996, p. 110), remaining in a state of culture shock, using previously held views to explain situations and evidence observed. Resisters' practice is teacher-centred, and they hold students responsible for their numerous classroom difficulties, looking for answers in management techniques. Conversely, rethinkers, who began their TE with comparable attitudes and beliefs, through developing relationships with students, moved away from their original deficiency orientation. They realised that the students' knowledge and skills went beyond their expectations, as did the interest in learning progress shown by parents (Gillette, 1996). This led these trainees to start to align their planning with the needs and identities of the students they were teaching; their approach to teaching and learning was as a shared responsibility between themselves and the students, professional behaviours which are directly at odds with those of resisters. A key pre-requisite for pre-service teachers to work effectively with ethnically diverse students is the development of personal relationships through personal sharing of self and showing care by asking students about their "interests, histories and cultural practices" (Valli, 1996, p. 284). These findings raise the issue of how teacher education programmes can ensure that trainees develop relationships with diverse students while on TE, so that they "recognize and build on assets students bring, interpret student classroom behaviour accurately, contextualise problems students bring within a socio-political rather than cultural deficiency analysis, and communicate constructively with adults in students' lives"' (Sleeter, 2008, p. 563).

Learning experiences designed to develop an authentic personal connection between the pre-service teacher and a student from another culture, over the course of a TE, are clearly valuable. This learning experience needs to be substantial, since the least intensive type of community-based learning, not including living in the community, tends to lead to a reduced impact (Sleeter, 2008). I believe that the greatest potential for such a task to lead to "perspective transformation" (Mezirow, 1990) would come where this interaction is primarily based outside the school setting. Some in-school aspects could also usefully improve the pre-service teacher's ideas for supporting student learning. Darling-Hammond (2002a) notes that such an inquiry helps teacher trainees to appreciate their students' life experience and perspective; her students commonly cite this as one of the most powerful learning experiences of their training, because of the insight it brings, and the improved self-efficacy that trainees subsequently feel (Darling-Hammond, 2002b). Beneficial preparation would include training in the use of ethnographic tools such as active listening, interviewing, and observation (Darling-Hammond, 2002b; Sleeter, 2008), so that trainee teachers apply knowledge about different cultural patterns in communication. From my experience teaching in schools with predominantly Polynesian communities, I am confident that many families would value the opportunity for such a positive connection. This would be enhanced by the demonstration of appreciation and valuing of the whanau's and family's time, commitment and knowledge, such as gifting back to them a record of the learning. Sharing of findings and artefacts upon return from TE, such as photos, video, and samples of student work, could provide valuable learning for the wider trainee group. The reliability of this task in assessing attitude and belief shifts is strengthened by requirements for evidence of a lesson designed specifically to motivate, engage and support the learning of the selected school student, and a reflective journal recording ongoing thoughts, feelings and ideas of the pre-service teacher throughout the time of the TE.

The readiness of pre-service teachers to engage and focus on students is also a function of their stage in training. Typically pre-service teachers begin by focusing on concerns about themselves, such as "How will I get them to do what I want?" This leads to concern for behaviour 
management and establishing themselves as the classroom manager. Only later do some trainees become attentive to students' needs, and begin to examine how they can best meet those needs. Indeed, some experienced teachers working in multicultural environments continue to regard student control as their fundamental principle of practice (Rios, 1996). This raises the question of when a multicultural experience can offer the best potential for gains. Burant and Kirby identify the benefit to pre-service teachers of developing relationships with families in the school community before TE, through community-based work (cited by Sleeter, 2008, p. 572). Sleeter herself argues that such an experience should occur early in training, to provide valuable preparation for the TE itself. However, such an experience can be overwhelming, leading to a reliance on long-held beliefs, thus unhelpfully reinforcing the lessons from early socialisation (Tiezzi \& Cross, 1997, cited by Sleeter, 2008, p. 569).

A TE allows trainees to observe first hand that what teachers do makes a difference; course planning and classroom pedagogical practice, when tailored to the needs of the students, will motivate and engage students, providing scaffolded learning experiences relating to content and contexts which are relevant and meaningful to the learners, resulting in successful achievement. This learning can come from observation of lessons which fail as well as observation of excellent classroom practice. Consideration of student achievement data reminds us that current teacher practitioners, notwithstanding their range of competencies, operate less than optimally, with achievement outcomes still showing significant ethnic disparity.

Benefits arise if pre-service teachers can see a variety of teaching models in action (Ross \& Smith, 1992, cited by Sleeter, 2008, p. 570). In order to maximise learning from observation experiences, pre-service teachers need to know how to critically analyse what they see, and develop ideas about possible improvements. Learning from observation of teacher practice improves with the use of guided reflection, leading trainees to consider the link between what the teacher planned and implemented in the lesson, and how students responded (Sleeter, 2008).

The value of TEs is constrained by a tendency for ATs to measure the pre-service teacher's success by his/her ability to maintain the status quo (Gillette, 1996). ATs holding deficit mindsets for ethnic minorities may actively resist alternative attitudes and introduction of culturally inclusive pedagogical practices, undermining emerging attitudes and beliefs for the pre-service teacher, which may already be frail due tolack of congruence with a lifetime of socialisation (Sleeter, 2008). Furthermore, when privileged "white" trainees have TEs in schools with monocultural policies, practices and systems, the resulting cultural compatibility reinforces dysconscious racism (Gillette, 1996). Alignment between teacher-educators and ATs to develop competency for multicultural education can be improved by means of formalised relationships between teacher-education providers and schools working explicitly with an agreed commitment to social equity (DarlingHammond, 2002a; Sleeter, 2008).

In summary, it seems that to maximise the learning for multicultural education from TE, trainee teachers need to be encouraged to develop: personal connections with students from different ethnic groups; support for this in the form of cultural knowledge and ethnographic skills; guided reflection skills; and access to ATs who challenge the deficit thinking model.

\section{Case Method}

Case method involves use of a teaching case to provide a framework for discussion and debate. The teaching case is a "story, describing or based on actual events and circumstances, that is told with a definite teaching purpose in mind and that rewards careful study and analysis" (Lynn, 1999 , p. 2). Case teaching involves small group analysis of questions relating to the assigned case, followed by whole class discussion facilitated by the teacher to focus thinking on the main concepts, and elicit and develop student ideas through the use of probing questions (Wassermann, 1994). This strategy is particularly suited to professional work because it allows for analysis of complex contextualised situations requiring high level thinking to determine the best way forward. Because cases can promote problem-solving related to the appropriate application of training to specific contexts, they develop trainees' conditional knowledge (Harrington, 1995, p. 203). However because case method teaching requires the sourcing or design of suitable stories, preparation of these complex resources creates manageability challenges for teacher educators.

Through careful study and discussion of realistic situations presented in cases, trainee teachers vicariously gain experience which is directly relevant to their future classroom practice. Consideration of cases in pre-service programmes allows time for reflection and discussion which professionals do not have access to in their working 
lives. The value is enhanced when students debate cases in heterogenous co-operative groups (Andrews, 1997), gaininginsights into alternative perspectives, and forcing explicit identification of beliefs, assumptions, and values underpinning individual perspectives on the case at hand (Harrington, 1995). It is a challenging task for teacher educators to support the successful development in trainees of all the qualities of expert critical thinkers, including not only awareness of their personal assumptions, but also qualities of critical self-reflection, and awareness of themselves as culturally located. Nevertheless Harrington (1995) found that some pre-service teachers show emerging consideration of the full range of consequences of their chosen actions, including impacts on the greater community, social justice, and the social-moral development of the students. Case-based teaching can develop reflective practice, once teachers appreciate the inherent cultural subjectivity of their personal worldview. This is the potential of case method which is visualised by Fenstermacher and Richardson (1991), who write:

One of the most powerful ways of effecting the reconstructing (of a prospective teacher's reasoning) is to address with the teacher the realisation that his actions have moral, stipulative, empirical and situational dimensions. In so doing (we) are assisting the teacher to complete his practical reasoning, by, in a sense, collecting in one place all the different motives, reasons, and grounds for taking a specific action. Once the practical argument is reasonably complete, it is then possible to look at its inferential properties, asking how the premises connect to one another and to the conclusion. (Cited by Harrington, 1995, p. 212)

Case method is a valuable training strategy when students are learning about "unfamiliar contexts, cultures, or problems" (Lynn, 1999, p. 39). Conversely, I believe that case method discussion regarding cases to illustrate situations involving Māori or Pasifika students, for instance, would improve after trainees had developed personal connections with individuals from these groups, possibly through their TE experiences.

\section{Interactive Performance}

Interactive Performance is a form of process drama undertaken in a school, which begins with pre-service teacher-participants researching "the social climate and culture" (Romano, 2007, p. 100) to develop a customised storyline around typical problems commonly faced by students. This form of process drama has its origins in Boal's Theatre of the Oppressed, developed by the Brazilian activist and dramatist Augusto Boal in the 1970 s, with the aim of liberating oppressed peoples through using drama to develop their ideas and attitudes regarding possible actions which could significantly impact on their lives (Pye, 2000).

A range of process drama devices are incorporated in Interactive Performance: role circle, thought tracking, and hot seating. Role circle means that the play is co-constructed by a group, using real-life experience as well as fictional elements, rather than solely from a specific experience of a particular individual. This allows the whole group to own the play, making the process safe for all participants. Thought tracking means that the audience may stop the action at any time to ask a character to explain their thoughts at that particular moment. Hot seating involves a convention whereby a seat is placed in front of the audience at the end of each scene, so that each character in turn may be cross-examined by audience members. Both thought tracking and hot seating promote deep thinking about attitudes, motivations and perspectives of individuals, simultaneously monitoring character authenticity. Evaluations indicate that hot-seating is the most powerful drama technique used within the process, effectively generating perceptive and insightful questions and responses (Burton \& O’Toole, 2005)

Interactive Performance is employed as a training strategy with pre-service teachers at Ohio University, where most students are middle- to upper-class urban Caucasians. After pre-service teacherparticipants research the interpersonal dynamics within the school, they develop a storyline related to the authentic life issues and concerns of those students. The developed play is presented to an interactive audience of students, teachers and administrators of the school itself, who together with the trainee-teacher-actors determine how to resolve the situation: during a second performance the play may be stopped at any time, on multiple occasions, allowing the audience to change the behaviour of any participant, including bystanders. This encourages thinking regarding the possible role of different parties in resolving the situation, and supports mediation skill development.

Interactive performance works by helping the pre-service teachers to know their students and know themselves. It requires the prospective teachers to fully develop an authentic student character and take on the role of that student, providing "a window through which to view the 
very experiences, dilemmas, perspectives, and challenges through which [the students] must negotiate their way" (Romano, 2007, pp. 100-101). The strategy promotes deeper understanding of different perspectives, and reflection on the possible impact of the actions of a teacher, or other students and individuals, on a person, and also allows trainees to design and rehearse proposed actions to prevent or alleviate undesirable situations. Weekly critical reflections evidence teacher trainees' changing attitudes towards the students, as they begin to appreciate the students' alternative perspectives, and also manifest the birth of new ideas about their personal teaching aims. New knowledge of students gained clarifies connections between students' difficulties and teaching practice; it stimulates thinking about how to make the curriculum relevant for the students, how to engage their self-interest, and how best to help them learn. Value also arises from the attendant self-analysis of conceptions and attitudes, as trainee teachers build their awareness of themselves as culturally located persons. Romano describes the impact on one particular pre-service teacher, from an upper-middle-class family:

He hadn't been aware of his own social class status before, even though he had taken courses in diversity in education and was committed to trying to understand his students who came from poor, working class, and other backgrounds different from his. The impact of the high school students' passion made a mark on him. He was now aware of what was invisible before, and because he played the role of a student who was discriminated against, this pre-service teacher desired to understand and learn how to relate in supportive ways to students of all classes. (Romano, 2007, p. 104)

This shift in self-awareness evidences the ability of Interactive Performance to develop authentic appreciation and identification with "the other," by creating experiential engagement for trainees with culturally diverse students. The extent to which this outcome is achieved depends on the management of the activity, and incorporation of opportunities for deep reflection. The overall timeframe of in-school time with students, time allowed for interaction, and quality of questioning and discussion will affect actual gains from this element. From my experience as a Pakeha woman working with Māori and Pasifika students, I would expect that time is needed for the students to develop trust, a pre-requisite to open and frank discussion.

The growth in respect for students, resulting from increased awareness of the complex challenges they face, can reasonably be expected to impact positively on the relationships between pre-service teachers and their students, which is particularly important for Polynesian students (Hawk et al., 2002). Participation in this training experience also led to developments in trainee teachers' awareness of, and commitment to, addressing social justice issues; they learned to "question, comment and challenge" (Romano, 2007, p. 102), and developed an appreciation of advocacy and critical action.

Successful Interactive Performance relies heavily on the effective enactment of the facilitator ("joker") role (Pye, 2000). The joker must ensure that the actors are supported to develop an authentic, relevant storyline; that actors have thoroughly engaged with their characters; that the audience is challenged through effective questioning to participate with commitment to designing action for a desirable outcome. Therein lies a challenge for teacher educators, to develop confidence and knowledge in their use of this complex drama technique. Use of Interactive Performance would necessitate training and experience of the strategy, to achieve appreciation of its potential, as well as confidence in leading it.

My personal observation of enactment of Enhanced Forum Theatre, a variation of this model, shows that pre-service teacher-participants display a range of willingness to engage. Shyness, introversion, and reticence can cause discomfort, and some are constrained by a belief that drama skills are required. A possible consequence is superficial, self-conscious participation; arguably the greatest impact in this case could be resistance. The facilitators' skill in briefing and prefacing the activity is a key influence in offsetting these problems.

Interactive Performance relies on the support of a school with a diverse student population, staffed by professionals who are comfortable with the process involved, including the nature of discussion and debate that will arise, which could be painful, difficult or controversial. Because the exercise is intrusive and time-consuming, the school needs to recognise and value highly the outcomes of the activity, for its school community. To make full use of this potentially valuable training strategy, professional development for teacher educators is also necessary, to develop the knowledge, skills and confidence required. Other key elements of the approach are significant investment of time to familiarise trainees with students in a school, and then develop the drama; as well as the use of critical reflection to support trainees' growing self-awareness and awareness of others. 


\section{Discussion}

A socio-cultural approach (Vygotsky, 1978) is particularly suitable for adults learning a complex profession, because it features situated learning (Lave, 1988), perceived as highly relevant because it is contextualised. Cases gain trainees' psychological and personal involvement because they are seen as significant and relevant (Dewey, 1964, cited by Lynn, 1999), thus engaging them on both the emotional and the cognitive level. This principle is also true for TEs and Interactive Performance, both grounded in authentic work contexts, highlighting situations which demand the attention of practising teachers.

To change "one's worldview and social interactions, implicit beliefs must be engaged and considered" (Valli, 1996, p. 283). This statement points to the value of constructivist tools such as sharing ideas and feelings (discussion conversation) and conscious development of awareness of assumptions held (dialogue conversation) to help trainee teachers bring meaning to their experiences (Argyris \& Schon, 1974). These tools also support the expression of personal theories, and active reflective engagement with one's self as a culturally located being. It is critical that training should allow pre-service teachers to "analyse the values and assumptions of different paradigms and theories" (Banks, 2001, p. 212), as a necessary precursor to discussion and debate, in order to build appreciation of alternative perspectives held by others. This also helps trainees develop their own ideas and begin to appreciate the selectivity of curriculum content and the values associated with that selection (Banks, 2001). The understanding lets students break through dysconscious racism: an "uncritical habit of mind" (King, 2004, p. 73) which is unquestioning of the status quo, and therefore gives tacit support to existing inequity and exploitation. These key processes of guided self-reflection, discussion, unlearning and relearning are embedded in training strategies such as interactive performance, case method and teaching experience, depending on the level of alignment between principles of multicultural education, the teacher education programme as a whole, and the professionals with whom teacher trainees interact. Training in ethnographic skills also supports the awakening of trainees to new perspectives on others and themselves, by minimising the risk of trainees unconsciously viewing individuals in unfamiliar ethnic groups through their own unrecognized cultural lens, thereby reinforcing current beliefs (Sleeter, 2008). Finally this process requires an absolutely safe learning environment, to offset risks of trainees feeling "attacked" and "made to feel guilty that they were white" (Hannon, 1990, cited by Ladson-Billings, 1991, p. 151).

\section{Implications}

Tremendous challenges face trainee teachers and teacher-educators in the task of developing helpful attitudes and beliefs for multicultural education, and current student achievement data confirm that success is still elusive.

Knowledge alone cannot change beliefs and attitudes, but "direct personal experience can" (Triandis, 1971, cited by Aguilar \& Pohan, 1996): this can happen when teacher trainees are forced to face dissonance and reconstruct their beliefs (Aguilar \& Pohan, 1996, p. 265), because these experiences create "transformational emotional growth" (King, 2004, p. 72). Thus opportunities for experiential learning coupled with guided reflection seem to offer the best chance for reconstructing attitudes and beliefs which support multicultural teaching competence. Such experiences must be non-confrontational for the participants (Bishop, Berryman, Tiakiwai \& Richardson, 2003, p. 204). Intensive experiences such as cultural immersion and community-based fieldwork yield promising results (Aguilar \& Pohan, 1996; Sleeter, 2008), but teacher-education programmes are constrained by the need for strategies which are both manageable and valid. Experiential learning however does require sufficient substance to make an impact, such as is hoped to be achieved by a TE or in the research and audience interaction stages of interactive performance. Valid and reliable assessment of attitudes and beliefs poses another challenge, which can be addressed by use of requirements for reflection on multiple contexts over time, and provision of evidence showing the impact of developing beliefs on practice.

Effective support for developing multicultural educators benefits from coherence, meaning that this theme is integrated across all aspects of the teacher-education programme, including shared norms and vision of faculty members and ATs in schools (Gillette, 1996). The combined presence of these aspects of a coherent programme strongly signals its importance (Sleeter, 2008). Room for improvement in alignment may be evidenced by a range of indicators, including for instance, addressing the needs of ethnically diverse learners in a single course; informal comments by faculty members regarding the difficulty associated with teaching in ethnically diverse schools; lack of modelling 
of good teaching practices for ethnically diverse student groups; all of which may be addressed by means of a strategic approach across the organisation to the development of multicultural educational competence. The degree of alignment achieved will also be affected by socio-political factors within the teacher-education institution, influencing decisions such as course content, assessment, and training strategies. For instance, in the Victoria University of Wellington College of Education, the timing of courses prevents some from using assessment activities directly linked to the TE. Financial considerations and other aims of universities, such as prioritising PBRF ratings, also impact on programme decisions. The existence of socio-political constraints means that teacher training institutions will achieve this alignment only when there is commitment to the principle of multicultural education and equitable student outcomes.

Most research I was able to find in preparing this article was generated overseas, particularly in the USA, where historical and societal factors are significantly different, although the key issues and indicators remain the same. American research signals challenges in supporting teacher trainees to transcend their monocultural life experience; undergoing transformative work is difficult and painful for the trainees and their instructors (Darling-Hammond, 2002a). Trainee teachers commonly believe that to affirm cultural difference is racist; to focus on diversity causes disunity; and social inequity is caused by socio-cultural deficits (King, 2004). Any newly-developing attitudes which a novice teacher may be nurturing are easily unsettled by the overwhelming presence of a lifetime of socialisation, and reinforcement of deficit theorising by some practising teachers. Successfully supporting the growth and development of effective multicultural educators in New Zealand therefore demands from us a commitment to develop our knowledge and understanding of the dynamics of the local situation. This highlights the value of further research, to explore our knowledge of trainee teachers' experiences in New Zealand, and to develop understanding of the effectiveness of alternative training strategies in supporting trainee teachers to be multicultural educators here. This type of evaluative research has the potential to inform the design of teacher training programmes, thus effectively supporting the country's vision of equity and achievement for all.

\section{References}

Aguilar, T. E., \& Pohan, C. A. (1996). Using a constructivist approach to challenge pre-service teachers' thinking about diversity education. In F. A. Rios (Ed.), Teacher thinking in cultural contexts (pp. 260-281). New York: State University of New York Press.

Andrews, L. (1997, February). Diversity: Changing perspectives using case-based methods. Paper presented at the annual meeting of the American Association of Colleges for Teacher Education, Phoenix, Arizona.

Argyris, C., \& Schon, D. (1974). Theory in practice: Increasing professional effectiveness. San Francisco, CA: Jossey-Bass.

Banks, J. A. (2001). Cultural diversity and education: Foundations, curriculum and teaching (4th ed.). Needham Heights, MA: Allyn \& Bacon.

Banks, J. (2007). Afterword. In C. Sleeter (Ed.), Facing accountability in education: Democracy and equity at risk (pp. 188-197). New York: Teachers College Press.

Bishop, R., Berryman, M., Tiakiwai, S., \& Richardson, C. (2003). Te Kotahitanga Phase 1: The experiences of Year 9 \& 10 Māori students in mainstream classrooms: Report to the Ministry of Education. Wellington: Learning Media.

Bondy, A., \& Savage, C. (2004, November). Creating critical conversations. Paper presented at the national conference of the New Zealand Association for Research in Education (NZARE), Wellington.

Burton B., \& O'Toole J. (2005). Enhanced forum theatre: Where Boal's Theatre of the Oppressed meets process drama in the classroom. NJ (Drama Australia Journal, 29(2), 49-57). Retrieved May 28, 2008 from <http://search.informit.com.au/fullText; $\mathrm{dn}=149401 ;$ res $=$ AEIPT > ISSN: 1445-2294.

Darling-Hammond, L. (2002a). Learning to teach for social justice. In L. Darling-Hammond, J. French, \& S. P. Garcia-Lopez (Eds.), Learning to teach for social justice (pp. 1-7). New York: Teachers College Press.

Darling-Hammond, L. (2002b). Educating a profession for equitable practice. In L. Darling-Hammond, J. French, \& S. P. Garcia-Lopez (Eds.), Learning to teach for social justice (pp. 201-216). New York: Teachers College Press. 
Dewey, J. (1964). The child and the curriculum. In John Dewey on education: Selected writings. Chicago, University of Chicago Press.

Fenstermacher, G., \& Richardson, V. (1991, April). The elicitation and reconstruction of practical arguments about teaching. Paper presented at the annual meeting of the American Educational Research Association, Chicago.

Gillette, M.D. (1996). Resistance and rethinking: White student teachers in pre-dominantly African-American schools. In F. A. Rios (Ed.), Teacher thinking in cultural contexts (pp. 104-128). New York: State University of New York Press.

Hannon, A. (1990, February 22). Weekend retreat generates heated feelings. The Santa Clara, p. 20.

Harrington, H. L. (1995). Fostering reasoned decisions: Case-based pedagogy and the professional development of teachers. Teaching and Teacher Education, 11(3), 203-214.

Hawk, K., Cowley, E.T., Hill, J., \& Sutherland, S. (2002). The importance of the teacher/student relationship for Māori and Pasifika students. set, 3, 44-49.

King, J. E. (2004). Dysconscious racism: Ideology, identity, and the miseducation of teachers. In G. Ladson-Billings \& D. Gillborn (Eds.), The Routledge-Falmer reader in multicultural education (pp. 71-83). London: Routledge-Falmer.

Ladson-Billings, G. (1991). Beyond multicultural illiteracy. The Journal of Negro Education, 60(2), 147-157.

Lave, J. (1988). Cognition in practice: Mind, mathematics, and culture in everyday life. Cambridge, UK: Cambridge University Press.

Lynn, L. E. Jr. (1999). Teaching and learning with cases: A guidebook. New York: Seven Bridges Press.

Mezirow, J. \& Associates. (1990). Fostering critical reflection in adulthood: A guide to transformative and emancipatory learning. San Francisco: Jossey Bass.

Ministry of Education. (2002). Briefing for the incoming Minister for Education 2002. Wellington: Learning Media.

Ministry of Education. (2007). The New Zealand Curriculum. Wellington: Learning Media.
106 Linda $\operatorname{Hogg}$

Pye, C. (2000). Introduction to forum theatre. QADIE Says, 23(1), 59-60. Retrieved May 28, 2008 from:

$<$ http://search.informit.com.au/fullText; $\mathrm{dn}=103376$;res =AEIPT $>$ ISSN: 0727-4432.

Rios, F. A. (1996). Teachers' principles of practice for teaching in multicultural classrooms. In F. A. Rios (Ed.), Teacher thinking in cultural contexts (pp. 129-148). New York: State University of New York Press.

Romano, R. M. (2007). Learning to act: Interactive performance and pre-service teacher education. In P. J. Finn \& M. E. Finn (Eds.), Teacher education with an attitude: Preparing teachers to educate working class students in their collective self-interest (pp. 95-107). Albany: State University of New York Press.

Sleeter, C. (2008). Preparing white teachers for diverse students. In M. Cochran-Smith, S. Feiman-Nemser, D. J. McIntyre, \& K. E. Demers (Eds.), Handbook of research on teacher education: Enduring questions in changing contexts (3rd ed.) (pp. 559-582). New York: Routledge, Taylor \& Francis Group and the Association of Teacher Educators.

Triandis, H. C. (1971). Attitude and attitude change. New York: Wiley.

Valli, L. (1996). Learning to teach in cross-cultural settings. In F. A. Rios (Ed.), Teacher thinking in cultural contexts (pp. 282-307). New York: State University of New York Press.

Vygotsky, L. S. (1978). Mind in society. Cambridge, MA: Harvard University Press.

Wassermann, S. (1994). Introduction to case method teaching: A guide to the galaxy. New York: Teachers College Press.

\section{The author}

Linda Hogg is a lecturer in the School of Educational Psychology and Pedagogyin the Faculty of Education, Victoria University of Wellington. Her current research interests are in teacher education, particularly the design of professional development tools to support effective teaching and learning for diverse learners. Currently she works with both trainee teachers and teachers in secondary schools. She has a background in secondary education, with more than 20 years of teaching in New Zealand and the Cook Islands. 